\title{
Differential effects of candesartan and olmesartan on adipose tissue activity biomarkers in type II diabetic hypertensive patients
}

\author{
Giuseppe Derosa $^{1}$, Pamela Maffioli ${ }^{1}$, Sibilla AT Salvadeo ${ }^{1}$, Ilaria Ferrari ${ }^{1}$, Alessia Gravina ${ }^{1}$, Roberto Mereu ${ }^{1}$, \\ Ilaria Palumbo ${ }^{1}$, Elena Fogari ${ }^{1}$, Angela D’Angelo ${ }^{1}$ and Arrigo FG Cicero ${ }^{2}$
}

The aim of this study is to compare the effects of candesartan and olmesartan on insulin sensitivity-related parameters, before and after antihypertensive therapy. After a 4-week washout placebo period, 194 hypertensive (diastolic blood pressure (DBP) $\geqslant 80 \mathrm{~mm} \mathrm{Hg}$ and systolic blood pressure (SBP) $\geqslant 130 \mathrm{~mm} \mathrm{Hg}$ ) patients with well-controlled type II diabetes were randomized to receive either $8 \mathrm{mg}$ of candesartan once a day (o.d.) or $10 \mathrm{mg}$ olmesartan o.d. and titrated after 1 month to $16 \mathrm{mg}$ candesartan o.d. or $20 \mathrm{mg}$ olmesartan o.d., respectively; the treatment period had a 1-year duration. We evaluated body weight, body mass index, SBP, DBP, glycated hemoglobin, fasting plasma glucose, $M$ value, adiponectin (ADN), resistin ( $r$ ), retinol-binding protein 4, visfatin, vaspin and high-sensitivity C-reactive protein (Hs-CRP) at their baseline values and after 6 and 12 months of treatment. We observed no variation in body weight or glycemic profile for either treatment. SBP and DBP were significantly reduced by both treatments (from $144 \pm 8 / 88 \pm 6$ to $126 \pm 5 / 77 \pm 4 \mathrm{~mm} \mathrm{Hg}$ by candesartan $(P<0.001$ ) and from $145 \pm 9 / 89 \pm 7$ to $128 \pm 7 / 79 \pm 5 \mathrm{~mm} \mathrm{Hg}$ by olmesartan $(P<0.001))$ without any difference between them. Retinol binding protein-4, $r$, and the vaspin value decreased in the candesartan group but not in olmesartan group. The $M$ value, visfatin and ADN increased with candesartan, whereas no significant variations were observed with olmesartan. Both treatments resulted in a similar reduction in Hs-CRP. Although both therapies resulted in similar reductions in blood pressure, candesartan therapy was more effective than olmesartan therapy in improving insulin sensitivity.

Hypertension Research (2010) 33, 790-795; doi:10.1038/hr.2010.85; published online 27 May 2010

Keywords: adipokines; candesartan; olmesartan; type II diabetes mellitus

\section{INTRODUCTION}

The renin-angiotensin-aldosteron system (RAAS) is involved in a large number of physiopathological processes leading to hypertension and increased cardiovascular risk. Apparently, the principal mediator of such processes is angiotensin II (AII). ${ }^{1}$

Evidence from animal models and cultured skeletal muscle cell line studies indicates that AII can induce insulin resistance, mediated by the impairment of insulin receptor substrate-1-dependent insulin signaling that is reversed by the administration of angiotensin receptor antagonism. ${ }^{2}$

In addition, recent literature shows that AII is also strongly involved in adipose tissue metabolism. In fact, both angiotensin type 1 and 2 receptors have been localized to adipocytes, and differences in the regional expression of RAAS components in visceral vs. subcutaneous adipose tissue have been used to explain the link between abdominal obesity and cardiovascular disease. ${ }^{3}$ Moreover, AII reduces the adipogenic response of adipocyte progenitor cells; the extent of this reduction correlates directly with the body mass index (BMI) of subjects, and the effects of AII can be reversed by type 1 angiotensin receptor antagonists. ${ }^{4}$ On the other hand, genetic deficiencies in the angiotensin type 2 receptor lead to reduced adipocyte differentiation and decreased adipocyte numbers in atherosclerotic mice. ${ }^{5}$ Recent in vitro data also suggest that the RAAS blockade induces the release of visfatin from adipocytes and that sartans are more powerful release inducers than angiotensin-converting enzyme inhibitors. ${ }^{6}$ This last point could be relevant to the current study because visfatin binds to insulin receptors at a site distinct from insulin and causes hypoglycemia by reducing glucose release from liver cells and stimulating glucose utilization in adipocytes and myocytes. ${ }^{7}$ The relationship between RAAS and other human adipokines such as resistin (r), retinol-binding protein 4 (RBP-4) and vaspin is still under investigation. However, it is well known that many of these molecules are associated with or involved in the development of hypertension, both as single risk factors and as components of the metabolic syndrome. ${ }^{8}$ As not all sartans exert similar metabolic effects on glucose meta-

\footnotetext{
${ }^{1}$ Department of Internal Medicine and Therapeutics, University of Pavia, Fondazione IRCCS Policlinico S. Matteo, PAVIA, Italy and ${ }^{2}$ Department of Internal Medicine, Aging and Kidney disease, University of Bologna, Bologna, Italy

Correspondence: Professor G Derosa, Department of Internal Medicine and Therapeutics, University of Pavia, Fondazione IRCCS Policlinico S. Matteo, Pavia, P.le C. Golgi 2, 27100 Pavia, Italy. 
bolism-related parameters ${ }^{9,10}$ or inflammation markers, ${ }^{11}$ we designed this study to test whether two different sartans with analogous levels of efficacy in the treatment of hypertension might nonetheless differ in their effects on a set of adipose tissue metabolism-related parameters.

\section{METHODS}

\section{Study design and patients}

This multicenter, randomized, double-blind clinical trial was conducted in the Department of Internal Medicine and Therapeutics at the University of Pavia and at the University of Bologna's 'G. Descovich' Atherosclerosis Study Center in the Department of Internal Medicine, Aging and Kidney Disease. The study protocol was approved at each site by the institutional review boards and conducted in accordance with the Declaration of Helsinki and its amendments.

\section{Patients}

We enrolled 194 Caucasian patients (99 males and 95 females, all $\geqslant 18$ years) who had hypertension (defined as having diastolic blood pressure (DBP) $\geqslant 80 \mathrm{~mm} \mathrm{Hg}$ and systolic blood pressure (SBP) $\geqslant 130 \mathrm{~mm} \mathrm{Hg}$ ) and well-controlled type II diabetes mellitus (glycated hemoglobin $\left.\left(\mathrm{HbA}_{1 \mathrm{c}}\right)<7 \%\right)$.

Patients with secondary hypertension, a history of ketoacidosis or with unstable or rapidly progressive diabetic retinopathy, nephropathy or neuropathy were excluded, as were patients with impaired liver function (defined as plasma aminotransferase (or aspartate aminotransferase, with normal values of $11-39 \mathrm{mU} \mathrm{ml}^{-1}$ ), alanine aminotransferase (normal values: $11-34 \mathrm{mU} \mathrm{ml}^{-1}$ ) and/or $\gamma$-glutamyltransferase (normal values: $\left.11-53 \mathrm{mU} \mathrm{ml}^{-1}\right)$ ), impaired kidney function (defined as serum creatinine level (normal values: $0.6-1.3 \mathrm{mg}$ per $100 \mathrm{ml})$ ) or anemia. Patients with unstable cardiovascular conditions (for example, New York Heart Association class I-IV congestive heart failure or a history of myocardial infarction or stroke) or past incidences of cerebrovascular conditions within 6 months of study enrollment were also excluded. Women who were pregnant, lactating, or who might become pregnant (due to inadequate contraceptive precautions) were also excluded. Patients with known contraindications or intolerance to sartans were also not included in the study.

\section{Treatments}

After a 4-week washout placebo period, patients were randomized to receive either $8 \mathrm{mg}$ candesartan once a day (o.d.) or $10 \mathrm{mg}$ olmesartan o.d. After 1 month, patients were titrated to dosages of $16 \mathrm{mg}$ candesartan o.d. or $20 \mathrm{mg}$ olmesartan o.d., respectively; the treatment period had a 1-year duration. Both candesartan and olmesartan were supplied as identical-looking, opaque white capsules in coded bottles to ensure the blind status of the study. Randomization was performed by drawing envelopes containing randomization codes prepared by a statistician. A copy of the code was provided only to the person responsible for performing the statistical analysis. The code was only broken after database lock, but it could have been broken for individual subjects in the event of an emergency. Medication compliance was assessed by counting the number of pills returned by patients at the time of their specified clinic visits. At baseline, we gave each patient a bottle containing a supply of study medication for at least 100 days. Throughout the study, we instructed patients to take their first dose of new medication on the day after they were given the study medication. At the same time, all unused medication was retrieved for inventory. All medications were provided free of charge.

Suitable subjects, identified from a review of case notes and/or computerized clinic registries were contacted in person or by telephone. All patients gave written informed consent.

\section{Laboratory methods}

Before starting the study, all patients underwent an initial screening assessment that included a medical history, a physical examination, a test of the patient's vital signs and a 12-lead electrocardiogram. We evaluated patients at the start of the study to establish baseline values, then again in the sixth and twelfth months of treatment, in terms of the following parameters: body weight, BMI, SBP, DBP, $\mathrm{HbA}_{1 \mathrm{c}}$, fasting plasma glucose, $M$ value, adiponectin $(\mathrm{ADN}), \mathrm{r}, \mathrm{RBP}-4$, visfatin, vaspin and high-sensitivity $\mathrm{C}$-reactive protein (Hs-CRP).

To evaluate the tolerability assessments, all adverse events were recorded. All plasmatic parameters were measured after the patients completed a 12-h overnight fast. In all cases, venous blood samples were taken between 0800 and 0900 hours. We used plasma obtained by the addition of $\mathrm{Na}_{2}$-EDTA $\left(1 \mathrm{mg} \mathrm{ml}^{-1}\right)$ and centrifuged at $3000 \mathrm{~g}$ for $15 \mathrm{~min}$ at $4^{\circ} \mathrm{C}$. Immediately after centrifugation, the plasma samples were frozen and stored at $-80^{\circ} \mathrm{C}$ for not more than 3 months. All measurements were performed in a central laboratory.

BMI was calculated as the patient's weight $(\mathrm{kg})$ divided by the square of his or her height $(\mathrm{m})$. Blood pressure measurements were obtained from patients' right arms while they were in a seated position, using a standard mercury sphygmomanometer (Erkameter 3000, ERKA, Bad Tolz, Germany) (Korotkoff I and V) with an appropriately sized cuff. Furthermore, the same investigator measured patients' blood pressure at each visit, always in the morning and after the patient had rested for at least $10 \mathrm{~min}$ in a quiet room. During each visit, three successive blood pressure readings were obtained at 1-min intervals, and the mean of the three readings was calculated.

$\mathrm{HbA}_{1 \mathrm{c}}$ level was measured by a high-performance liquid chromatography method (DIAMAT, Bio-Rad, Richmond, CA, USA; normal values $4.2-6.2 \%$ ), with intra- and inter-assay coefficients of variation $(\mathrm{CsV})$ of $<2 \% .^{12}$ Plasma glucose was assayed by the glucose-oxidase method (GOD/PAP, Roche Diagnostics, Mannheim, Germany) with intra- and inter-assay $\mathrm{CsV}$ of $<2 \%$. $^{13}$

ADN level was determined using enzyme-linked immunosorbent assay (ELISA) kits (B-bridge International, Sunnyvale, CA, USA). Intra-assay $\mathrm{CsV}$ were $3.6 \%$ for low-control samples and $3.3 \%$ for high-control samples, whereas inter-assay CsV were 3.2 and $7.3 \%$ for low- and high-control samples, respectively. ${ }^{14}$

We used a commercially available ELISA kit (BioVendor Laboratory Medicine, Brno, Czech Republic) to measure resistin values. In this study, intra-assay $\mathrm{CsV}$ was $3.4 \%$ and inter-assay $\mathrm{CsV}$ was $6.9 \%{ }^{15}$

RBP-4 was measured using an RBP-4 (human) enzyme immunoassay kit (Phoenix Pharmaceuticals, Burlingame, CA, USA). Intra- and inter-assay $\mathrm{CsV}$ were less than $5.0 \%$ and less than $14.0 \%$, respectively. ${ }^{16}$

An enzyme immunoassay kit obtained from Phoenix Pharmaceuticals was used to measure visfatin levels, and their intra- and interassay $\mathrm{CsV}$ were 10 and $<14 \%$, respectively. ${ }^{17}$

Vaspin was measured by a two-site ELISA method using commercially available ELISA kits (Adipogen, Seoul, Korea); the intra- and inter-assay $\mathrm{CsV}$ were 1.74 and $8.32 \%$, respectively. ${ }^{18}$

Hs-CRP was measured using latex-enhanced immunonephelometric assays on a BN II analyzer (Dade Behring, Newark, DE, USA). The intra- and inter-assay CsV were 5.7 and $1.3 \%$, respectively. ${ }^{19}$

\section{Glucose clamp technique}

We assessed patients' insulin sensitivity ( $M$ value) using the euglycemic, hyperinsulinemic clamp, according to the technique of De Fronzo et al. ${ }^{20}$ At 0900 hours, after the subject had fasted for $12 \mathrm{~h}$ overnight, an intravenous catheter ( $18 \mathrm{~g}$ polyethylene cannula, Venflon, Viggo, 
Halsingborg, Sweden) was placed into an antecubital vein for the infusion of insulin and a $20 \%$ glucose solution. A second catheter was inserted retrogradely into a wrist vein. The patient's hand was heated (to about $70^{\circ} \mathrm{C}$ ) in a thermoregulated box with the aim of arterializing venous blood within 20-40 min. ${ }^{21}$ Plasma glucose levels were assessed at 5- or 10-min intervals during application of the clamp. A 10-min priming infusion of insulin (Humulin R, Lilly Corporate, Indianapolis, IN, USA) was administered at a rate of $1 \mathrm{mU} \mathrm{min}^{-1} \mathrm{~kg}^{-1}$ for $2 \mathrm{~h}$, during which time the patient's plasma glucose concentration was held constant at the basal state $(95 \mathrm{mg}$ per $100 \mathrm{ml})$ by a variable infusion of exogenous glucose. The amount of glucose required to maintain isoglycemia is equal to the patient's whole-body disposal of glucose, provided that endogenous glucose production is essentially absent. During insulin infusion, normal fasting blood glucose levels were maintained by adjusting the rate of infusion of a $20 \%$ glucose solution. The $M$ value (the amount of glucose infused, that is, whole-body glucose disposal, expressed as $\mu \mathrm{mol}$ per minute per kilogram of body weight $\left(\mu \mathrm{mol} \mathrm{min} \mathrm{mg}^{-1} \mathrm{~kg}^{-1}\right)$ ) was calculated as the mean value for each 20 -min interval during the last $60 \mathrm{~min}$ of the clamp application.

\section{Statistical analysis}

An intention-to-treat analysis was conducted in patients who had received $\geqslant 1$ dose of study medication and had a subsequent efficacy observation. Patients were included in the tolerability analysis if they had received $\geqslant 1$ dose of trial medication and had undergone a subsequent tolerability observation. Considering as clinically significant a difference of at least $10 \%$ compared with the baseline and an alpha error of 0.05 , our sample size was adequate to obtain a power higher than 0.80 for all measured variables. Continuous variables were evaluated using repeated analysis of variance (ANOVA) tests. Intervention effects were adjusted for the presence of potential confounding variables using analysis of covariance (ANCOVA). ANOVA was also used to assess the significance of variables within and between groups. The statistical significance of the independent effects of treatments on the other variables was determined using ANCOVA. Paired tests were also used: a one-sample $t$-test was used to compare values obtained before and after treatment, and two-sample $t$-tests were used for between-group comparisons. ${ }^{22}$ Statistical analysis of data was performed using the Statistical Package for Social Sciences software, version 14.0 (SPSS, Chicago, IL, USA). The data are presented as the mean \pm s.d. For all statistical analyses, $P<0.05$ was considered statistically significant.

\section{RESULTS}

Study sample

A total of 194 patients were enrolled in the study. Of these, 187 completed the study; $94(50.3 \%)$ were allocated to the candesartan group and 93 (49.7\%) were assigned to the olmesartan group. There were seven patients (four males and three females) who did not complete the study. Their reasons for premature withdrawal included side effects such as dizziness (one male in the olmesartan group after 6 months of treatment), headache (one male in the candesartan group after 6 months), nausea (one female in the candesartan group after 6 months), being lost to follow-up (one male in the candesartan group after 6 months), protocol violation (one female in the olmesartan group after 12 months), noncompliance (one male in the olmesartan group after 12 months) and administrative (one female in the candesartan group after 12 months). The characteristics of the patient population on entering the study are shown in Table 1, whereas the antidiabetic agents taken before and during the study are shown in Table 2.
Table 1 General subjects characteristics at baseline in the study

\begin{tabular}{lcc}
\hline & Candesartan & Olmesartan \\
\hline$N$ & 98 & 96 \\
Sex (M/F) & $50 / 48$ & $49 / 47$ \\
Age (years) & $57 \pm 6$ & $56 \pm 5$ \\
Sm. st. (M/F) & $15 / 11$ & $13 / 12$ \\
Diab. dur. (years) & $5 \pm 2$ & $6 \pm 3$ \\
Height (m) & $1.69 \pm 0.04$ & $1.68 \pm 0.03$ \\
& & \\
Concomitant disease, $n$ (\%) & $94(95.9)$ & $92(95.8)$ \\
Hypercholesterolemia & $36(38.3)$ & $31(32.3)$ \\
Hypertriglyceridemia & $6(6,4)$ & $4(4.2)$ \\
Combined dyslipidemia & $13(13.8)$ & $15(15.6)$ \\
& & \\
Concurrent medications, $n$ (\%) & $98(100)$ & $96(100)$ \\
ACE-I & $19(19.4)$ & $22(22.9)$ \\
$\alpha$-Blockers & $6(6.1)$ & $8(8.3)$ \\
Calcium antagonists & $17(17.3)$ & $16(16.7)$ \\
$\beta$-Blockers & $8(8.1)$ & $9(9.4)$ \\
Diuretics & $23(23.5)$ & $20(20.8)$ \\
Statins & $44(44.9)$ & $41(42.7)$ \\
Fibrates & $13(13.3)$ & $15(15.6)$ \\
Omega-3 & $18(18.4)$ & $20(20.8)$ \\
Acetylsalicylic acid & $89(90.8)$ & $88(91.7)$ \\
Ticlopidine & $5(5.1)$ & $4(4.2)$ \\
\hline
\end{tabular}

Abbreviations: ACE-I, angiotensin-converting enzyme inhibitors; diab. dur., diabetes duration; F, female; M, male; Sm. st., smoking status.

Data are expressed as means \pm s.d. or $n$ and \%.

\section{Blood pressure}

We observed significant improvements in patients' SBP and DBP, compared with their baseline values, after 6 and 12 months on either treatment (for SBP, $P<0.01$, and for DBP, $P<0.001$, for both drugs), without any significant differences between the two groups (Tables 3 and 4).

\section{Body weight}

We did not observe any significant variations in body weight or BMI for either of the treatments (Tables 3 and 4).

\section{Glycemic profile}

We did not register any variations in $\mathrm{HbA}_{1 \mathrm{c}}$, or fasting plasma glucose in either of the groups (Tables 3 and 4).

\section{Inflammatory parameters}

A significant improvement on baseline values of $\mathrm{ADN}$ was recorded in the candesartan group after 12 months of treatment $(P<0.05)$, whereas no differences were observed in the olmesartan group; furthermore, $\mathrm{ADN}$ values in the candesartan group were significantly higher than ADN values in the olmesartan group after 1 year of treatment (Tables 3 and 4).

After 12 months of treatment, the candesartan group experienced a significant decrease in vaspin from baseline values $(P<0.05)$. The olmesartan group did not share this decrease, and the difference between the two groups was significant $(P<0.01)$ (Tables 3 and 4).

Hs-CRP in both groups decreased from baseline values after 6 months of treatment and after 12 months (for both drugs, $P<0.05$ and $P<0.01$, respectively), with no significant differences between the two treatments (Tables 3 and 4 ). 
Table 2 Antidiabetic agents before and during the study

\begin{tabular}{|c|c|c|}
\hline & Candesartan & Olmesartan \\
\hline$n$ & 98 & 96 \\
\hline$O H A, \mathrm{n}(\%)$ & 95 (96.9) & $94(97.9)$ \\
\hline Sulphonylureas, $n(\%)$ & $15(15.8)$ & $12(12.8)$ \\
\hline Glyburide & $6(40.0)$ & $5(41.7)$ \\
\hline Glimepiride & $8(53.3)$ & $5(41.7)$ \\
\hline Gliclazide & $1(6.7)$ & $2(16.6)$ \\
\hline Biguanides, $n(\%)$ & $34(35.8)$ & $33(35.1)$ \\
\hline Metformin & $34(100)$ & $33(100)$ \\
\hline Glinides, $n(\%)$ & $11(11.6)$ & $12(12.8)$ \\
\hline Repaglinide & $10(90.9)$ & $10(83.3)$ \\
\hline Nateglinide & $1(9.1)$ & $2(16.7)$ \\
\hline$\alpha$-Glucosidase inhibitors, $n(\%)$ & $24(25.3)$ & $27(28.7)$ \\
\hline Acarbose & $24(100)$ & $27(100)$ \\
\hline Thiazolidinediones, n (\%) & $38(40)$ & $31(33.0)$ \\
\hline Pioglitazone & $24(63.2)$ & $20(64.5)$ \\
\hline Rosiglitazone & $14(36.8)$ & $11(35.5)$ \\
\hline Incretin mimetics, $n(\%)$ & $8(8.4)$ & $9(9.6)$ \\
\hline Exenatide & $8(100)$ & $9(100)$ \\
\hline DPP-4 inhibitors, $n(\%)$ & $13(13.7)$ & $10(10.6)$ \\
\hline Sitagliptin & $9(69.2)$ & $6(60)$ \\
\hline Vildagliptin & $4(30.8)$ & $4(40)$ \\
\hline Insulin, n (\%) & $8(8.2)$ & $6(6.2)$ \\
\hline Analog, $n(\%)$ & $8(100)$ & $6(100)$ \\
\hline Lispro & $3(37.5)$ & $2(33.3)$ \\
\hline Aspart & $2(25.0)$ & $1(16.7)$ \\
\hline Glulisine & $3(37.5)$ & $3(50)$ \\
\hline Long-acting, $n(\%)$ & $8(100)$ & $6(6.4)$ \\
\hline Glargine & $3(37.5)$ & $2(33.3)$ \\
\hline Detemir & $1(12.5)$ & $1(16.7)$ \\
\hline $\mathrm{NPH}$ & $4(50.0)$ & $3(50)$ \\
\hline
\end{tabular}

Abbreviations: DPP-4, dipeptidyl peptidase-4 inhibitors; NPH, neutral protamine Hagedorn; $\mathrm{OHA}$, oral hypoglycemic agents.

Data are expressed as $n$ or \%.

\section{Insulin resistance parameters}

In the candesartan group, we observed a significant improvement in $M$ values after 12 months $(P<0.05)$, whereas no differences were observed in the olmesartan group; $M$ values obtained for candesartan were significantly better than those for olmesartan after 12 months of treatment $(P<0.05)$ (Tables 3 and 4$)$.

At 12 months after the baseline values were established, a significant decrease in $\mathrm{r}$ was recorded in the candesartan group $(P<0.05)$, but not in the olmesartan group; moreover, the value reached using candesartan was significantly better than the value reached with olmesartan $(P<0.05)$ (Tables 3 and 4$)$.

RBP-4 significantly improved after 12 months' treatment with candesartan $(P<0.01)$, whereas no differences were recorded in the olmesartan group compared to its baseline values. The two groups' outcomes in this area after a year of treatment differed significantly $(P<0.05)$ (Tables 3 and 4$)$.

In the candesartan group, visfatin increased after 12 months compared with the baseline $(P<0.05)$, whereas visfatin showed no change in the olmesartan group. Furthermore, the values recorded for candesartan were significantly better than the values observed for olmesartan after 12 months of treatment $(P<0.05)$ (Tables 3 and 4$)$.
Table 3 Patients data during the study in candesartan group

\begin{tabular}{|c|c|c|c|}
\hline & Baseline & At 6 months & At 12 months \\
\hline$n$ & 98 & 95 & 94 \\
\hline $\operatorname{Sex}(M / F)$ & $50 / 48$ & $48 / 47$ & $48 / 46$ \\
\hline Sm. st. (M/F) & $22 / 20$ & $22 / 20$ & $22 / 19$ \\
\hline Weight (kg) & $76.3 \pm 6.9$ & $75.8 \pm 6.4$ & $76.2 \pm 6.8$ \\
\hline $\mathrm{BMI}\left(\mathrm{kg} \mathrm{m}^{-2}\right)$ & $26.7 \pm 1.2$ & $26.5 \pm 1.0$ & $26.7 \pm 1.2$ \\
\hline $\mathrm{SBP}(\mathrm{mm} \mathrm{Hg})$ & $144 \pm 8$ & $134 \pm 6^{* *}$ & $126 \pm 5^{\dagger}$ \\
\hline $\mathrm{DBP}(\mathrm{mm} \mathrm{Hg}))$ & $88 \pm 6$ & $82 \pm 4^{* *}$ & $77 \pm 3^{\dagger}$ \\
\hline $\mathrm{HbA}_{1 \mathrm{c}}(\%)$ & $6.4 \pm 0.5$ & $6.3 \pm 0.4$ & $6.3 \pm 0.4$ \\
\hline FPG (mg per $100 \mathrm{ml}$ ) & $123 \pm 11$ & $121 \pm 10$ & $120 \pm 9$ \\
\hline \multirow[t]{3}{*}{$M$ value $\left(\mu \mathrm{mol} \mathrm{min}^{-1} \mathrm{~kg}\right)$} & $3.48 \pm 0.43$ & $3.91 \pm 0.87$ & $4.97 \pm 1.3^{*, \dagger \dagger}$ \\
\hline & $4.7 \pm 1.1$ & $5.1 \pm 1.3$ & $5.6 \pm 1.5^{*,+\dagger}$ \\
\hline & $6.6 \pm 1.9$ & $6.3 \pm 1.7$ & $5.8 \pm 1.4^{* \dagger \dagger}$ \\
\hline $\mathrm{ADN}\left(\mu \mathrm{g} \mathrm{ml^{-1 }}\right)$ & $65.9 \pm 22.8$ & $53.1 \pm 16.9$ & $45.2 \pm 14.3^{* *, \dagger}$ \\
\hline$r\left(n g \mathrm{ml}^{-1}\right)$ & $31.8 \pm 19.7$ & $34.6 \pm 20.7$ & $39.7 \pm 25.1^{*,+\uparrow}$ \\
\hline Vaspin (ngml-1) & $0.7 \pm 0.3$ & $0.6 \pm 0.2$ & $0.4 \pm 0.1^{*, \dagger}$ \\
\hline Hs-CRP $\left(\mathrm{mg} \mathrm{l}^{-1}\right)$ & $1.8 \pm 0.9$ & $1.4 \pm 0.7^{*}$ & $1.1 \pm 0.5^{* *}$ \\
\hline
\end{tabular}

Abbreviations: AND, adiponectin; BMI, body mass index; DBP, diastolic blood pressure; F, female; FPG, fasting plasma glucose; $\mathrm{HbA}_{1}$, glycated hemoglobin; Hs-CRP, high-sensitivity C-reactive protein; M, male; r, resistin; RBP-4, retinol binding protein-4; SBP, systolic blood pressure; Sm. st., smoking status.

Data are means \pm s.d.

${ }^{\star} P<0.05$ vs. baseline; ${ }^{*} P<0.01$ vs. baseline; ${ }^{\dagger} P<0.001$ vs. baseline; ${ }^{\dagger} P<0.05$ vs. olmesartan.

FPG: to convert from $\mathrm{mg}$ per $100 \mathrm{ml}$ to $\mathrm{mmol}^{-1}$, multiply by 0.0555 .

Table 4 Patients data during the study in olmesartan group

\begin{tabular}{|c|c|c|c|}
\hline & Baseline & At 6 months & At 12 months \\
\hline$n$ & 96 & 95 & 93 \\
\hline $\operatorname{Sex}(M / F)$ & $49 / 47$ & $48 / 47$ & $47 / 46$ \\
\hline Sm. st. $(M / F)$ & 20/19 & $19 / 19$ & $19 / 19$ \\
\hline Weight (kg) & $75.6 \pm 6.2$ & $75.1 \pm 6.0$ & $75.7 \pm 6.3$ \\
\hline $\mathrm{BMI}\left(\mathrm{kg} \mathrm{m}^{-2}\right)$ & $26.8 \pm 1.3$ & $26.6 \pm 1.1$ & $26.8 \pm 1.3$ \\
\hline $\mathrm{SBP}(\mathrm{mm} \mathrm{Hg})$ & $145 \pm 9$ & $136 \pm 7 * *$ & $128 \pm 6^{\dagger}$ \\
\hline $\mathrm{DBP}(\mathrm{mm} \mathrm{Hg}))$ & $89 \pm 7$ & $83 \pm 5^{* *}$ & $79 \pm 4^{\dagger}$ \\
\hline $\mathrm{HbA}_{1 \mathrm{c}}(\%)$ & $6.3 \pm 0.4$ & $6.3 \pm 0.4$ & $6.2 \pm 0.3$ \\
\hline FPG (mg per $100 \mathrm{ml}$ ) & $121 \pm 10$ & $120 \pm 9$ & $119 \pm 8$ \\
\hline$M$ value $\left(\mu \mathrm{mol} \mathrm{min}-1 \mathrm{~kg}^{-1}\right)$ & $3.46 \pm 0.42$ & $3.65 \pm 0.64$ & $3.96 \pm 0.91$ \\
\hline $\operatorname{ADN}\left(\mu g \mathrm{ml}^{-1}\right)$ & $4.6 \pm 1.0$ & $4.8 \pm 1.1$ & $4.9 \pm 1.2$ \\
\hline$r\left(n g m l^{-1}\right)$ & $6.8 \pm 2.0$ & $6.5 \pm 1.8$ & $6.3 \pm 1.7$ \\
\hline RBP-4 ( $\left.\mu g \mathrm{ml}^{-1}\right)$ & $63.7 \pm 21.2$ & $61.2 \pm 20.8$ & $59.2 \pm 19.1$ \\
\hline Visfatin (ng ml-1) & $30.7 \pm 18.9$ & $32.5 \pm 19.9$ & $34.0 \pm 20.2$ \\
\hline Vaspin (ng ml-1) & $0.8 \pm 0.4$ & $0.8 \pm 0.4$ & $0.8 \pm 0.4$ \\
\hline Hs-CRP (mg I-1) & $1.7 \pm 0.8$ & $1.2 \pm 0.6^{*}$ & $1.0 \pm 0.4^{* *}$ \\
\hline
\end{tabular}

Abbreviations: AND, adiponectin; BMI, body mass index; DBP, diastolic blood pressure; $F$ female; FPG, fasting plasma glucose; $\mathrm{HbA}_{1 c}$, glycated hemoglobin; Hs-CRP, high sensitivity-C reactive protein; M, male; r, resistin; RBP-4, retinol binding protein-4; SBP, systolic blood reactive protein; $M$, male; $r$, resist
pressure; $\mathrm{Sm}$. st., smoking status.

pressure; Sm. st., smoking status.
${ }^{*} P<0.05$ vs. baseline; ${ }^{* *} P<0.01$ vs. baseline; ${ }^{\dagger} P<0.001$ vs. baseline.

Data are means \pm s.d.

FPG: to convert from $\mathrm{mg}$ per $100 \mathrm{ml}$ to $\mathrm{mmol}^{-1}$, multiply by 0.0555 .

\section{Correlations}

Stepwise multilinear regression analysis was performed to establish which metabolic factors could best predict the changes in insulin resistance $(M$ value). Significant predictors of such changes in the candesartan group were $\operatorname{ADN}(r=0.59, P<0.05)$ (Figure 1a), r $\quad(r=-0.57, P<0.05) \quad$ (Figure 1b), RBP-4 $(r=-0.64, P<0.01)$ (Figure 1c), visfatin $(r=0.53, P<0.05)$ (Figure 1d) and vaspin $(r=-0.51, P<0.05)$ (Figure 1e). Other correlation analyses did not indicate additional patterns of associations. 
a
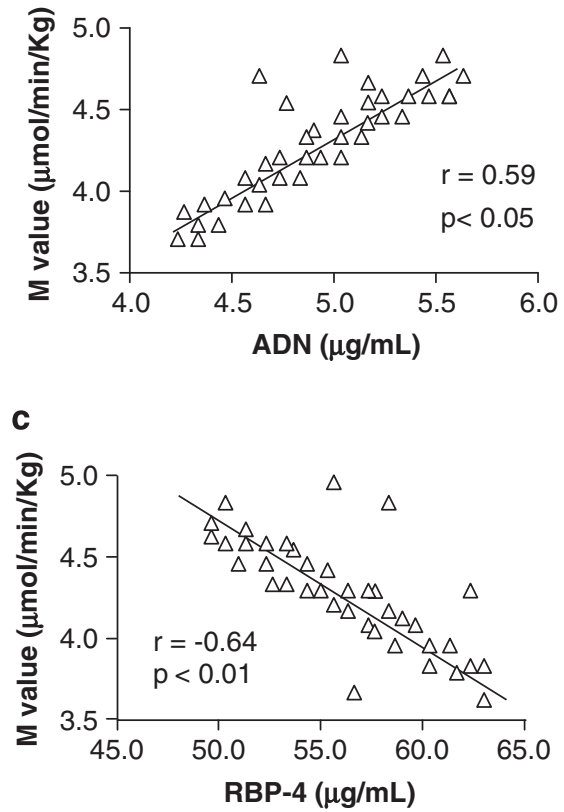

b
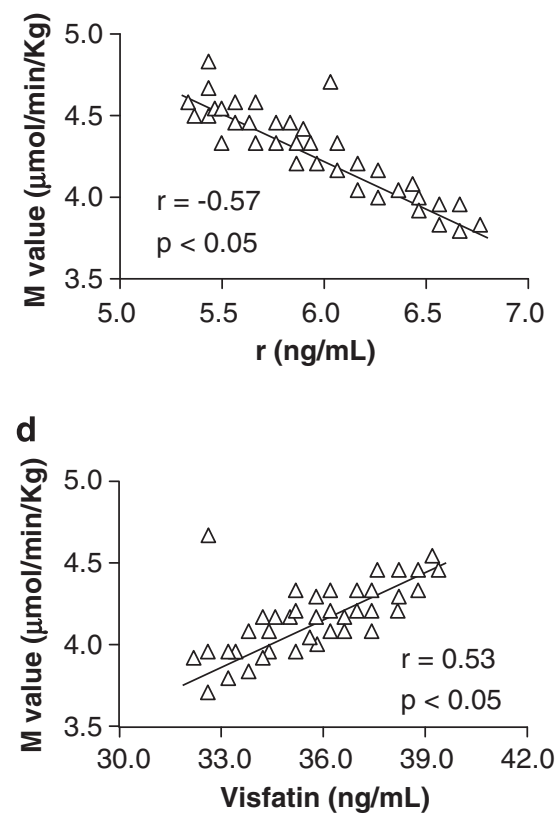

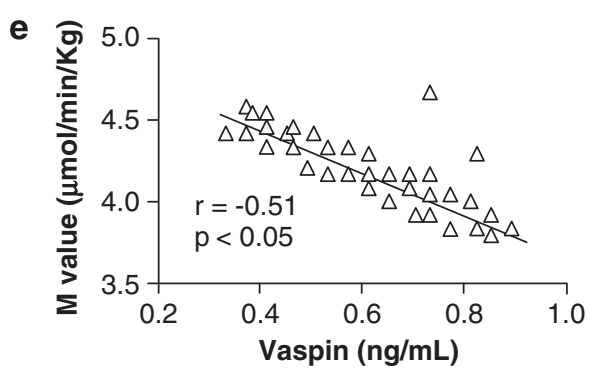

Figure 1 Significant correlations in the candesartan group, (a) correlation between adiponectin (ADN) and $M$ value; (b) correlation between resistin ( $r$ ) and $M$ value; (c) correlation between retinol binding protein-4 (RBP-4) and $M$ value; (d) correlation between visfatin and $M$ value; (e) correlation between vaspin and $M$ value.

\section{DISCUSSION}

Activation of the renin-angiotensin system (RAS) in adipose tissue may represent an important link between obesity and hypertension: blockage of the RAS, either by an angiotensin-converting enzyme inhibitor or an AII receptor blocker, results in a substantial increase in $\mathrm{ADN}$ levels and improved insulin sensitivity. ${ }^{23}$

In our study, carried out on hypertensive, overweight, type II diabetics, we observed that, despite having similar antihypertensive and anti-inflammatory effects, candesartan exerted specific effects on adipose tissue metabolism that were not observed for olmesartan. In particular, patients treated with candesartan experienced a significant improvement in their $M$ values $(+43.1 \%), \mathrm{ADN}(+19.1 \%)$, r (-12.1\%), RBP-4 (-31.4\%), visfatin (+21.7\%) and vaspin $(-42.8 \%)$. These changes were significant when compared with the results for the olmesartan group, and they were not observed among those treated with olmesartan.

The beneficial effects of both olmesartan ${ }^{24}$ and candesartan ${ }^{25}$ on blood pressure were already known. With regard to the effects of candesartan and olmesartan on adipokines, we know that $\mathrm{ADN}$ is a protein exclusively synthesized by adipocytes, which decreases in obese patients and is inversely related to glucose and insulin. ${ }^{26}$ ADN stimulates the oxidation of fatty acids and suppresses gluconeogenesis, and it inhibits monocyte adhesion, macrophage transformation, and the proliferation and migration of smooth muscle cells in blood vessels. ${ }^{14,27,28}$ On the contrary, $\mathrm{r}$ is produced by mononuclear cells and activated macrophages; it has been demonstrated that overexpression of $r$ decreases the ability of insulin to suppress hepatic glucose output or increase glucose uptake by muscle. ${ }^{29-31}$ Available data also suggest that $r$ has a role in increased incidences of inflammation and atherosclerosis. ${ }^{32}$ Increased concentrations of RBP4 have been reported in subjects diagnosed with obesity, insulin resistance or type II diabetes mellitus. ${ }^{33}$ Visfatin was discovered as a secretory protein that is highly enriched in human visceral adipocytes, yet it is also expressed by liver, muscle, bone marrow and lymphocytes. $^{34,35}$ The expression and secretion of visfatin increase during the development of obesity. However, the rise in visfatin does not decrease insulin sensitivity; visfatin exerts insulin-mimetic effects, binding to the insulin receptor with a similar affinity to insulin but at a site distinct from insulin. ${ }^{34}$ Vaspin (visceral adipose tissue-derived serpin), a member of the serine protease inhibitor family, was isolated from the visceral white adipose tissue (WAT) of Otsuka Long-Evans Tokushima fatty (OLETF) rats, a breed used to model abdominal obesity, insulin resistance and diabetes. ${ }^{18}$ Vaspin expression increases after 30 weeks, coinciding with obesity and high insulin levels in OLETF rats, and it declines as diabetes worsens and the rats lose weight by 50 weeks. Importantly, the administration of vaspin to obese mice improves their glucose tolerance and insulin sensitivity and reverses the expression of half of the WAT genes activated by 
diet-induced obesity. ${ }^{18} \mathrm{Hs}$-CRP has been shown to independently predict myocardial infarction, stroke and peripheral artery disease. ${ }^{36}$ With regard to the effects of candesartan on these parameters, previous research has already demonstrated that candesartan has a positive effect on $\mathrm{ADN} ;{ }^{37,38}$ to the best of our knowledge, though, this paper is the first to demonstrate the effects of candesartan on a large range of adipokines and adipose tissue metabolism-related parameters. Olmesartan's lack of effects on adipokines relative to candesartan has also been observed by de Vinuesa et al. ${ }^{39}$ in patients with chronic kidney diseases. In this study, we tested the highest available dosage of olmesartan, and so we can conclude that the drug's observed ineffectiveness was not due to an insufficient dose.

Our study has some limitations. First of all, the sample size is relatively small and the follow-up period is relatively short. Thus, we could hypothesize that the metabolic effects that we observed might also appear in the olmesartan-treated patients with a longer follow-up. In fact, in a previous study comparing the effects of two different sartans (telmisartan and irbesartan) on adipokine levels, these effects actually did appear earlier with telmisartan than irbesartan. ${ }^{40}$ Moreover, we did not evaluate the baseline distribution of adipose tissue in our patients, so we could not be sure that patients were equally distributed between the two treatment groups with regard to visceral adiposity. However, the patients were matched according to many anagraphic, clinical and metabolic parameters (including waist circumference and BMI), so we feel confident that the patients were adequately randomized.

In conclusion, in our short-term clinical trial, carried out on hypertensive, overweight, type II diabetics, we observed that, despite the two drugs having similar antihypertensive and anti-inflammatory effects, only candesartan (but not olmesartan) affects adipose tissue metabolism by improving $M$ values, $\mathrm{ADN}, \mathrm{r}, \mathrm{RBP}-4$, visfatin and vaspin levels.

\section{ACKNOWLEDGEMENTS}

The authors certify that they have no affiliation with, or financial involvement in, any organization or entity with a direct financial interest in the subject matter or materials discussed in this paper.

1 Steckelings UM, Rompe F, Kaschina E, Unger T. The evolving story of the RAAS in hypertension, diabetes and CV disease: moving from macrovascular to microvascular targets. Fundam Clin Pharmacol 2009; 23: 693-703.

2 Henriksen EJ. Improvement of insulin sensitivity by antagonism of the renin-angiotensin system. Am J Physiol Regul Integr Comp Physiol 2007; 293: 974-980.

3 Cassis LA, Police SB, Yiannikouris F, Thatcher SE. Local adipose tissue reninangiotensin system. Curr Hypertens Rep 2008; 10: 93-98.

4 Brucher R, Cifuentes M, Acuna MJ, Albala C, Rojas CV. Larger anti-adipogenic effect of angiotensin II on omental preadipose cells of obese humans. Obesity 2007; 15: 1643-1646.

5 Iwai M, Tomono Y, Inaba S, Kanno H, Senba I, Mogi M, Horiuchi M. AT2 receptor deficiency attenuates adipocyte differentiation and decreases adipocyte number in atherosclerotic mice. Am J Hypertens 2009; 22: 784-791.

6 Storka A, Vojtassakova E, Mueller M, Kapiotis S, Haider DG, Jungbauer A, Wolzt M. Angiotensin inhibition stimulates PPARgamma and the release of visfatin. Eur J Clin Invest 2008; 38: 820-826.

7 Adeghate E. Visfatin: structure, function and relation to diabetes mellitus and other dysfunctions. Curr Med Chem 2008; 15: 1851-1862.

8 Rasouli N, Kern PA. Adipocytokines and the metabolic complications of obesity. J Clin Endocrinol Metab 2008; 93(11 Suppl 1): S64-S73

9 Fogari R, Zoppi A, Ferrari I, Mugellini A, Preti P, Lazzari P, Derosa G. Comparative effects of telmisartan and eprosartan on insulin sensitivity in the treatment of overweight hypertensive patients. Horm Metab Res 2009; 41: 893-898.

10 Derosa G, Fogari E, D’Angelo A, Cicero AF, Salvadeo SA, Ragonesi PD, Ferrari I, Gravina A, Fassi R, Fogari R. Metabolic effects of telmisartan and irbesartan in type 2 diabetic patients with metabolic syndrome treated with rosiglitazone. J Clin Pharm Ther 2007; 32: $261-268$.

11 Nakayama S, Watada H, Mita T, Ikeda F, Shimizu T, Uchino H, Fujitani Y, Hirose T, Kawamori R. Comparison of effects of olmesartan and telmisartan on blood pressure and metabolic parameters in Japanese early-stage type-2 diabetics with hypertension. Hypertens Res 2008; 31: 7-13.
12 Bunn HF, Gabbay KH, Gallop PM. The glycosylation of haemoglobin. Relevance to diabetes mellitus. Science 1978; 200: 21-27.

13 European Diabetes Policy Group. A desktop guide to type 2 diabetes mellitus. Diabet Med 1999; 16: 716-730.

14 Yamauchi T, Kamon J, Waki H, Terauchi Y, Kubota N, Hara K, Mori Y, Ide T, Murakami K, Tsuboyama-Kasaoka N, Ezaki O, Akanuma Y, Gavrilova O, Vinson C, Reitman ML, Kagechika H, Shudo K, Yoda M, Nakano Y, Tobe K, Nagai R, Kimura S, Tomita M, Froguel $\mathrm{P}$, Kadowaki T. The fat-derived hormone adiponectin reverses insulin resistance associated with both lipoatrophy and obesity. Nature Med 2001; 7: 941-946.

15 Yannakoulia M, Yiannakouris N, Bluher S, Matalas AL, Klimis-Zacas D, Mantzoros CS. Body fat mass and macronutrient intake in relation to circulating soluble leptin receptor, free leptin index, adiponectin, and resistin concentrations in healthy humans. J Clin Endocrinol Metabol 2003; 88: 1730-1736.

16 Takebayashi K, Suetsugu M, Wakabayashi S, Aso Y, Inumai T. Retinol binding protein-4 and clinical features of type 2 diabetes patients. J Clin Endocrinol Metab 2007; 92: 2712-2719.

17 Korner A, Garten A, Bluher M, Tauscher R, Kratzsch J, Kiess W. Molecular characteristics of serum visfatin and differential detection by immunoassays. J Clin Endocrinol Metab 2007; 92: 4783-4791.

18 Hida K, Wada J, Eguchi J, Zhang H, Baba M, Seida A, Hashimoto I, Okada T, Yasuhara A, Nakatsuka A, Shikata K, Hourai S, Futami J, Watanabe E, Matsuki Y, Hiramatsu R, Akagi S, Makino H, Kanwar YS. Visceral adipose tissue-derived serine protease inhibitor: a unique insulin-sensitizing adipocytokine in obesity. Proc Natl Acad Sci 2005; 102: 10610-10615.

19 Rifai N, Tracy RP, Ridker PM. Clinical efficacy of an automated high-sensitivity C-reactive protein assay. Clin Chem 1999; 45: 2136-2141.

20 De Fronzo RA, Tobin JA, Andres B. Glucose clamp technique, a method for quantifying insulin secretion and resistance. Am J Physiol 1979; 237: 214-223.

21 Ferrannini E, Buzzigoli G, Bonadonna R, Giorico MA, Oleggini M, Graziadei L, Pedrinelli $\mathrm{R}$, Brandi L, Bevilacqua S. Insulin resistance in essential hypertension. N Eng/ J Med 1987; 317: 350-357.

22 Winer BJ. Statistical Principles in Experimental Design. 2nd edn. McGraw-Hill, New York, 1971.

23 Segura J, Ruilope LM. Obesity, essential hypertension and renin-angiotensin system. Public Health Nutr 2007; 10: 1151-1155.

24 Sugihara M, Miura S, Takamiya Y, Kiya Y, Arimura T, Iwata A, Kawamura A, Nishikawa $H$, Uehara $Y$, Saku K. Safety and efficacy of antihypertensive therapy with add-on angiotensin II type 1 receptor blocker after successful coronary stent implantation. Hypertens Res 2009; 32: 625-630.

25 Derosa G, Maffioli P, Salvadeo SA, Ferrari I, Gravina A, Mereu R, Palumbo I, D'Angelo A, Cicero AF. Candesartan effect on inflammation in hypertension. Hypertens Res 2010; 33: 209-213.

26 Jackson MB, Ahima RS. Neuroendocrine and metabolic effects of adipocyte-derived hormones. Clin Sci 2006; 110: 143-152.

27 Berg AH, Combs TP, Scherer PE. ACRP30/adiponectin: an adipokine regulating glucose and lipid metabolism. Trends Endocrinol Metab 2002; 13: 84-89.

28 Berg AH, Combs TP, Du X, Brownlee M, Scherer PE. The adipocyte-secreted protein Acrp30 enhances hepatic insulin action. Nat Med 2001; 7: 947-953.

29 Steppan CM, Bailey ST, Bhat S, Brown EJ, Banerjee RR, Wright CM, Patel HR, Ahima RS, Lazar MA. The hormone resistin links obesity to diabetes. Nature (London) 2001; 409: 307-312.

30 Satoh H, Nguyen MT, Miles PD, Imamura T, Usui I, Olefsky JM. Adenovirus-mediated chronic 'hyper-resistinemia' leads to in vivo insulin resistance in normal rats. J Clin Invest 2004; 114: 224-231.

31 Rangwala SM, Rich AS, Rhoades B, Shapiro JS, Obici S, Rossetti L, Lazar MA. Abnormal glucose homeostasis due to chronic hyperresistinemia. Diabetes 2004; 53: 1937-1941.

32 Reilly MP, Lehrke M, Wolfe M, Rohatgi A, Lazar MA, Rader DJ. Resistin is an inflammatory marker of atherosclerosis in humans. Circulation 2005; 111: 932-939.

33 Cho YM, Youn BS, Lee H, Lee N, Min SS, Kwak SH, Lee HK, Park KS. Plasma retinolbinding protein-4 concentrations are elevated in human subjects with impaired glucose tolerance and type 2 diabetes. Diabetes Care 2006; 29: 2457-2461.

34 Fukuhara A, Matsuda M, Nishizawa M, Segawa K, Tanaka M, Kishimoto K, Matsuki Y, Murakami M, Ichisaka T, Murakami H, Watanabe E, Takagi T, Akiyoshi M, Ohtsubo T, Kihara S, Yamashita S, Makishima M, Funahashi T, Yamanaka S, Hiramatsu R, Matsuzawa Y, Shimomura I. Visfatin: a protein secreted by visceral fat that mimics the effects of insulin. Science 2005; 307: 426-430.

35 Hug C, Lodish HF. Visfatin: a new adipokine. Science 2005; 307: 366-367.

36 Rifai N, Tracy RP, Ridker PM. Clinical efficacy of an automated high-sensitivity C-reactive protein assay. Clin Chem 1999; 45: 2136-2141.

37 Furuya R, Odamaki M, Kumagai $\mathrm{H}$, Hishida A. Impact of angiotensin II receptor blocker on plasma levels of adiponectin and advanced oxidation protein products in peritoneal dialysis patients. Blood Purif 2006; 24: 445-450.

38 Furuhashi M, Ura N, Higashiura K, Murakami H, Tanaka M, Moniwa N, Yoshida D, Shimamoto K. Blockade of the renin-angiotensin system increases adiponectin concentrations in patients with essential hypertension. Hypertension 2003; 42: 76-81.

39 De Vinuesa SG, Goicoechea M, Kanter J, Puerta M, Cachofeiro V, Lahera V, GómezCampderá $\mathrm{F}$, Luño J. Insulin resistance, inflammatory biomarkers, and adipokines in patients with chronic kidney disease: effects of angiotensin II blockade. J Am Soc Nephrol 2006; 17 (12 Suppl 3): S206-S212.

40 Derosa G, Cicero AF, D'Angelo A, Ragonesi PD, Ciccarelli L, Piccinni MN, Pricolo F, Salvadeo SA, Ferrari I, Gravina A, Fogari R. Telmisartan and irbesartan therapy in type 2 diabetic patients treated with rosiglitazone: effects on insulin-resistance, leptin and tumor necrosis factor-alpha. Hypertens Res 2006; 29: 849-856. 